\title{
Sedición (Delito de) Sedition (Crime of)
}

\author{
Rafael Rebollo Vargas \\ Universidad Autónoma de Barcelona \\ ORCID ID 0000-0002-7149-2984 \\ rafael.rebollo@uab.cat
}

\section{Cita recomendada:}

Rebollo Vargas, R. (2019). Sedición (Delito de). Eunomía. Revista en Cultura de la Legalidad, 17, 299-313.

doi: https://doi.org/10.20318/eunomia.2019.5035

Recibido / received: 03/06/2019 Aceptado / accepted: 28/08/2019

\begin{abstract}
Resumen
El delito de sedición se ubica sistemáticamente en el Código penal como un delito contra el orden público, por lo que su objeto de tutela y sus fines nada tienen que ver con una «rebelión en pequeño», a pesar de que algunas resoluciones recientes de la Audiencia Nacional y del propio Tribunal Supremo lo desnaturalicen hasta el punto de atribuirle unas finalidades que no se corresponden con su actual configuración típica.
\end{abstract}

\section{Palabras clave}

Delitos contra la Constitución, delitos contra el orden público, rebelión, sedición, alzamiento público y violento, alzamiento público y tumultuario.

\begin{abstract}
The sedition crime is located systematically in the Penal code as a crime against the public order, for what its object of tutelage and its ends not at all they have to do with a "rebellion in child", although some recent resolutions of the National Audience and of the proper Supreme Court denature it up to the point of attributing to him a few purposes that do not correspond to its current typical configuration.
\end{abstract}

\section{Keywords}

Crimes against the Constitution, crimes against public order, rebellion, sedition, violent and public uprising, public uprising and tumultuary.

SUMARIO. 1. Consideraciones Generales. 2. Delitos contra el orden público y sedición. 3. El alzamiento público y tumultuario en la sedición. 4. La maleabilidad del delito de sedición en el reciente tratamiento jurisprudencial. 4.1. El Auto del Juzgado Central de Instrucción núm. 3, de 27 de septiembre de 2017: las mixturas con el Código penal de 1973, la confusión con el delito de rebelión y la competencia de la Audiencia Nacional cuando el delito de sedición atente contra la forma de Gobierno. 4.2. El auto de la Sala de lo Penal 
de la Audiencia Nacional de 6 de noviembre de 2017: la corroboración del malabarismo jurídico y la confusión entre los delitos de rebelión, de sedición y la confirmación de la competencia de la Audiencia Nacional. 4.3. El Auto del Juzgado Central de Instrucción núm. 3, de 19 de febrero de 2018: más de lo mismo, la atribución al Comisario Jefe de la Policía Autonómica de un segundo delito de sedición y de un delito de organización criminal del art. 570 bis del Código penal. 4.4. El corolario de lo anterior: el Auto de procesamiento del Juzgado Central de Instrucción núm. 3, de 4 de abril de 2018, y la imputación a los procesados, entre otros, de un delito de sedición.

\section{Consideraciones Generales}

El delito de sedición es uno de los ilícitos al que la doctrina le ha prestado muy poca atención y sobre el que, hasta ahora, apenas existían pronunciamientos de los Tribunales. En todo caso, si hay dos particularidades que caracterizan a este delito es que, en primer lugar, una referencia en común de todos los trabajos que lo han abordado es el que se caracterice como una «rebelión en pequeño». Calificación que ha hecho una cierta fortuna en la doctrina, que se atribuye a Viada y Vilaseca $(1926,298)$ y que, no comparto ${ }^{1}$. Una vez afirmado lo anterior, y desde un punto de vista absolutamente antagónico, me parece oportuno anticipar cuál es mi criterio a ese respecto que, en realidad, no difiere del propuesto en su momento por García Rivas, quien de manera contundente afirma que sólo un desconocimiento jurídico «supino» ha podido emparejar este delito con el de rebelión, pues, mientras que el delito de rebelión supone un ataque a la estructura del Estado, la sedición es una infracción de orden bien distinta (2007, p. 1059)2.

La otra característica de los trabajos que se han dedicado al análisis del delito de sedición es que invariablemente hay una Sentencia del Tribunal Supremo que deviene en cita obligada, la de 10 de octubre de 1980. Una resolución que, si bien es ilustrativa ya que realiza un cierto análisis histórico de la trayectoria de este delito hasta incluir pequeñas referencias de derecho comparado o, incluso, particularizar los elementos que componían el comportamiento típico entonces vigente, se dicta bajo la todavía vigencia de un Código penal franquista, por ello, en clave preconstitucional. En todo caso, el momento histórico por el que atraviesa nuestro país, así como la sucesión de distintas y controvertidas resoluciones de los tribunales de justicia ha hecho surgir un inusitado interés por un delito que, probablemente, debería de haber sido derogado por el legislador en una de las tantas reformas llevadas a cabo en tan poco tiempo que, en realidad, lo han convertido en irreconocible si adoptamos como punto de referencia el Código penal de 1995.

En todo caso, es el Código penal de 1995 quien de forma inequívoca establece las diferencias entre ambos delitos, rebelión y sedición, al ubicarlos bajo rúbricas distintas. El delito de rebelión en el Capítulo I del Título XXI, «Delitos contra la Constitución» (arts. 472 y ss.), mientras que el delito de sedición se dispone en el Capítulo I del Título XXII, «Delitos contra el orden público» (arts. 544 y ss.), lo cual, de inicio, supone que con independencia de la descripción típica de ambos comportamientos o de sus finalidades, el objeto de protección es distinto y dispar a

\footnotetext{
1 Vid., al respecto Quintano Ripollés, quien hace ya muchos años afirmaba: «Es casi un lugar común, en materia de sedición, recurrir a la frase de Viada y Vilaseca de que no es otra cosa que una rebelión en pequeño» (1966, p. 555).

${ }^{2}$ Cfr., también sobre esta cuestión, Sandoval Coronado (2018, pp. 39-40).
} 
lo previsto en el Código penal de 1973 donde, como se recordará, se tipificaban en los Capítulos III y IV -respectivamente, arts. 214 y ss., y, 218 y ss.- además de compartir en el Capítulo $\mathrm{V}$ unas disposiciones comunes, todo ello bajo la rúbrica del Título II, «Delitos contra la seguridad interior del Estado» (Rebollo Vargas, 2018).

Es probable que el origen de la, llamémosle así, «confusión» en la subsunción típica de determinados comportamientos se produce como consecuencia de la querella que en su momento interpuso el Foro de Ermua contra el Lehendakari del Gobierno Vasco por el denominado «Plan Ibarretxe», así como contra «aquellos que pudieran aparecer como responsables de los hechos que se relatan a lo largo de la instrucción» por la presunta comisión de un delito de conspiración para la rebelión o, subsidiariamente, por un delito de conspiración para la sedición. Acción penal que el Tribunal Superior de Justicia del País Vasco (Sala de lo Civil y Penal), mediante su Auto 11/2005, de 1 de marzo, deniega su admisión a trámite y archiva las actuaciones ya que, afirma, reproduciendo la opinión del Fiscal, que: «el Estado de Derecho tiene mecanismos suficientes al margen del Derecho Penal, para, en esta fase que nos encontramos, frenar todo tipo de planteamientos políticos que no se ajusten a los procedimientos y cauces legales constitucionalmente establecidos».

Sea como fuere, continúa el Tribunal, la rebelión es un delito contra la Constitución, que se describe típicamente por la acción de alzarse, violenta y públicamente, para cualquiera de los fines previstos en el art. 472 del Código penal; mientras que la sedición es un delito contra el orden público, que se caracteriza por la existencia de un «alzamiento, en este caso, público y tumultuario», añadiendo que no cabe deducir, ni siquiera indiciariamente, que se haya producido un concierto de voluntades entre el Lehendakari y otras personas con el serio y firme designio, ya de alzarse, "violenta y públicamente, para derogar, suspender o modificar total o parcialmente la Constitución y/o declarar la independencia de una parte del territorio nacional, ya de alzarse, pública y tumultuariamente, para impedir por la fuerza o fuera de las vías legales, la aplicación de las Leyes o a cualquier autoridad [...] el legítimo ejercicio de sus funciones...».

Siguiendo el iter de los entonces querellantes, las acciones penales en las que se atribuía a los investigados la comisión de, entre otros, la comisión de un delito de rebelión y subsidiariamente de sedición se han sucedido en Cataluña, a pesar de que sucesivamente se inadmitían por el Tribunal Superior de Justicia de Cataluña (TSJC).

A pesar de lo anterior, de que la ceremonia de confusión en relación a la imputación de estos delitos parecía haber perdido intensidad, el Juzgado Central de Instrucción núm. 3, mediante su Auto de 27 de septiembre de 2017, acuerda incoar Diligencias Previas a instancias del Ministerio Fiscal, por un delito de sedición contra los dirigentes de Ómnium Cultural y la Asamblea Nacional Catalana, como consecuencia de los hechos ocurridos en Barcelona durante los días 20 y 21 de septiembre de 2017, en relación a las concentraciones y manifestaciones llevadas a cabo «para impedir por la fuerza la actuación de las autoridades y sus agentes en el ejercicio de sus funciones en defensa del ordenamiento constitucional». En todo caso, me interesa destacar en este momento una parte del Razonamiento Jurídico 
Tercero, donde, para arrogarse la competencia ${ }^{3}$, el Juzgado afirma que le corresponde:

No porque los delitos de sedición con carácter general sean competencia de la Audiencia Nacional, sino porque el delito de sedición que trata de investigar el Ministerio Fiscal en este caso puede atentar también contra la forma de gobierno «al tratar de cambiar ilegalmente la organización territorial del Estado y declarar la independencia de una parte del territorio nacional», lo que determina la competencia de la Audiencia Nacional conforme al art. 65.1.a) de la Ley Orgánica del Poder Judicial ${ }^{4}$.

Resolución que, como no podía ser de otra manera, se inicia con la inevitable cita de la Sentencia del Tribunal Supremo, de 10 de octubre de 1980, para asegurar, seguidamente, que el bien jurídico protegido en este delito es el orden público, además de tutelarse el principio de autoridad, lo cual parece contradictorio con la afirmación del Auto que acabamos de reproducir y que viene a superponer, una vez más, los delitos de rebelión y sedición ${ }^{5}$, a pesar de que sus ámbitos de protección, su ubicación en el Código penal, las finalidades que persiguen ambos ilícitos o los elementos que configuran la descripción típica de cada comportamiento ilícito sea la que es ${ }^{6}$.

\section{Delitos contra el orden público y sedición}

Una cuestión sobre la que es imprescindible detenerme es el concepto de orden público, asumido por una buena parte de la doctrina y que, con más o menos matices, caracterizan como «tranquilidad pública», lo vinculan con la «paz pública», «tranquilidad material», "convivencia colectiva» o «manifestaciones colectivas de la vida cotidiana»; nótese como, sin ir más lejos, en el actual art. $557 \mathrm{CP}$, delito de desórdenes públicos, uno de los elementos nucleares que describe el comportamiento típico previsto en el tipo es el de alteración de la «paz pública», ampliándose de esa forma la conducta incriminada en el precepto anterior a la reforma ya que en él se exigía la presencia de un elemento subjetivo del injusto «con el fin de alterar la paz pública» que, ahora, no se requiere.

En relación con lo anterior, creo que no es aventurado afirmar que se trata de fórmulas ambiguas e indeterminadas que, considero, no contribuyen a perfilar un concepto de orden público en clave constitucional, en particular porque se trata de una noción que adquiere una nueva dimensión con la entrada en vigor de la Constitución de 1978, centrándose ahora, básicamente, en el respeto inexcusable a los derechos fundamentales y libertades públicas constitucionalmente reconocidos (STC 43/1986, de 15 de abril).

Es verdad que el Tribunal Constitucional, en ocasiones, ha usado esas fórmulas que me suscitan importantes dudas por su ambigüedad o incluso ha

\footnotetext{
3 Resolución que, con similares argumentos a los formulados por el Magistrado Instructor, fue confirmada en apelación por la Sala de lo Penal de la Audiencia Nacional en su Auto 467/2017, de 6 de noviembre. Vid. no obstante, el Voto Particular del Magistrado De Prada Solaesa.

${ }^{4}$ Al respecto, Dopico Gómez-Aller (2017, passim).

${ }^{5}$ En este sentido, Fernández Rodera (1996, p. 1531), donde afirma que: "Se ha llegado a definir la sedición como una rebelión en pequeño o una "rebelión de segundo grado"». Fórmula que vuelve a emplear el mismo autor en 2015, p. 403.

${ }^{6}$ Vid., Manzanares Samaniego (2016): «El núcleo de la acción en el delito de rebelión es el alzamiento violento y público mientras que la sedición consiste en un alzamiento público y tumultuario, de forma que, según se adelantó, no sólo difieren los objetos perseguidos sino las propias conductas típicas»
} 
utilizado conceptos afines que ha empleado indistintamente como sinónimos o, desde luego, como semejantes. Una muestra de ello, entre otras muchas, es la STC 184/1995, de 12 de diciembre, FJ 3, «Es cierto -hemos dicho ya- que el concepto de "paz pública" o de orden público puede comprender, en un sentido amplio, el de "tranquilidad pública" y que el principio de reserva de Ley no impide la utilización de conceptos jurídicos indeterminados como el que nos ocupa en la tipificación de infracciones». Ahora bien, nótese que en este caso, como en otros muchos (SSTC 24/2015, de 16 de febrero, FJ 4; STC 193/2011, de 12 de diciembre, FJ 4; 163/2006, de 22 de mayo, FJ 3), la «paz pública se articula como límite al ejercicio de los derechos fundamentales».

Sin embargo, creo que se debe de invertir el objeto e interpretar el concepto de orden público en sentido positivo, además de que no puede considerarse como un límite implícito de los derechos fundamentales, sino que ese límite ha de venir expresamente previsto en el texto constitucional. Esto es, no me parece admisible limitar el ejercicio de los derechos fundamentales atendiendo a un concepto tan polémico como el de «orden público constitucional», interpretándolo como un conjunto de valores implícitos en nuestro texto constitucional (Carro FernándezValmayor, 1990, p. 11) ${ }^{7}$. Es más, como el propio Tribunal Constitucional ha dicho en repetidas ocasiones:

La primacía de la Constitución no debe confundirse con una exigencia de adhesión positiva a la norma fundamental, porque en nuestro ordenamiento constitucional no tiene cabida un modelo de "democracia militante», esto es, «un modelo en el que se imponga, no ya el respeto, sino la adhesión positiva al ordenamiento y, en primer lugar, a la Constitución» (STC 48/2003, FJ 7; doctrina reiterada, entre otras, en las SSTC 5/2004, de 16 de enero, FJ 17; 235/2007, FJ 4; 12/2008, FJ 6, y 31/2009, de 29 de enero, FJ 13). Este Tribunal ha reconocido que tienen cabida en nuestro ordenamiento constitucional cuantas ideas quieran defenderse y que «no existe un núcleo normativo inaccesible a los procedimientos de reforma constitucional" (entre otras, STC 31/2009, FJ 13)».

Como es bien sabido, en el texto constitucional el orden público actúa como límite al ejercicio de los derechos únicamente en dos ocasiones. El primero de ellos es el art. 16.1, derecho a la libertad ideológica, religiosa y de culto, donde la única limitación que se le impone es «la necesaria para el mantenimiento del orden público protegido por la ley». Asimismo, el art. 21.2, establece como límite al derecho de reunión, que solo podrá prohibirse «cuando existan razones fundadas en la alteración del orden público, con peligro para personas y bienes». Por lo tanto, como sostiene Carro Fernández-Valmayor, no puede adjudicarse al concepto de «orden público» un carácter metajurídico sino que, continúa, existe en el propio texto constitucional un orden público definido y delimitado por las leyes (1990, p. 13). Así es, la expresión utilizada en el art. 21.2 CE «alteración del orden público, con peligro para personas o bienes», es un mecanismo de carácter preventivo con motivo de la celebración de reuniones o manifestaciones que debe vincularse a razones de peligro objetivo para personas o bienes y no, desde luego, en criterios subjetivos o puramente valorativos, esto es, el contenido del orden público se concreta en el respeto de los derechos fundamentales, de las leyes y de los derechos de los demás.

Criterio que parece asumir el Tribunal Constitucional en el FJ 4 de su Sentencia 193/2011, de 12 de diciembre, donde refiere que la prohibición o la restricción del derecho de manifestación requiere una alteración del «orden público poniendo en peligro la integridad de las personas o de los bienes o suponga un

\footnotetext{
${ }^{7}$ Asimismo, ampliamente, vid. De Bartolomé Cenzano (2002, pp. 439-ss).
} 
sacrificio desproporcionado de otros bienes y valores constitucionalmente protegibles. Esto es así porque, como también hemos reiterado, «en una sociedad democrática el espacio urbano no es sólo un ámbito de circulación, sino también un espacio de participación» (entre otras, SSTC 66/1995, de 8 de mayo, FJ 3; 195/2003, de 27 de octubre, FJ 9; 90/2006, de 27 de marzo, FJ 2). A lo que puntualiza el propio Tribunal un poco más adelante que la alteración del orden público, «entendido como desorden material», puede justificar la imposición de límites al ejercicio del derecho (Sandoval Coronado, pp. 40-41).

En definitiva, lo que no me parece asumible es la delimitación del concepto de orden público partiendo de criterios como los referidos con anterioridad, esto es, los de «mantenimiento de la tranquilidad ciudadana», "tranquilidad pública», "paz pública», «tranquilidad material», «convivencia colectiva» o «manifestaciones colectivas de la vida cotidiana».

En este sentido, de acuerdo con Álvarez García, se ha de superar un concepto de orden público que lo identifica como «tranquilidad en la calle (2014, p. $29)^{8} \gg$. En efecto, el citado autor propone un concepto de orden público en sentido positivo, esto es, descarta un concepto material de orden público y propone sustituirlo por otro que se refiera a la «participación plena de los ciudadanos en la vida pública». El ejercicio público de derechos constitucionales, como los de reunión o manifestación no pueden entenderse, a priori, como una situación en la que el orden público resulte comprometido, sino como su plena realización, formando parte de su propio contenido.

Así, no puede obviarse la STC 19/1985, de 13 de febrero, donde en su FJ 1 se afirma que «el respeto a los derecho fundamentales y libertades públicas garantizados por la Constitución es un concepto esencial del orden público», por ello, continúa Álvarez García, las protestas, reuniones, manifestaciones públicas han de ser entendidas no como presupuestos de la alteración del orden público, sino como expresión de participación ciudadana en la reafirmación o confirmación del «orden constitucional, cuyo desarrollo no sólo no debe ser obstaculizado o reprimido sino alentado» (2014, p. 30). Es más, continúa, los tipos penales no han de configurarse partiendo del presupuesto de que son los derechos de reunión o de manifestación los que deben ceder ante cualquier alteración en la posibilidad de realización de otros derechos, sino que han de adecuarse esos derechos pretendidamente afectados a una situación de conflicto. Por ello, el ejercicio del derecho de reunión o de manifestación sólo puede condicionarse cuando existan fundadas razones de alteración del orden público, con peligro para personas o bienes; en todo caso, el concepto de orden público ha de construirse integrado con el ejercicio de derechos constitucionales. En suma, un concepto de orden público que atienda a conceptos tan flexibles, subjetivos y ambiguos como «tranquilidad en la calle» no puede actuar de otra manera que no sea la de un mecanismo cercenador del ejercicio de derechos y libertades (Álvarez García, 2014, p. 30).

\section{El alzamiento público y tumultuario en la sedición}

El delito de rebelión se caracteriza por un alzamiento violento y público con el que se pretende alcanzar determinados fines; por su parte, el alzamiento público y

\footnotetext{
8 Autor, que citando a Martín Retortillo enfatiza en la necesidad de superar la "trivialización" del concepto de orden público. Vid., Martín Retorillo (1983, pp. 298), quien afirma que el orden público es una "expresión odiosa que hubiera sido muy conveniente haber superado". Asimismo, particularmente crítico con la denominación de la rúbrica del T. XXII, Polaino Navarrete (1996, pp. 827-828).
} 
tumultuario característico de la sedición tiene un objeto distinto. Es decir, el «alzamiento» es intrínseco a ambas modalidades típicas, a pesar de que el bien jurídico protegido en ambos delitos es distinto. En uno es el sistema constitucional y en otro el orden público. Creo, por lo tanto, que no sólo se trata de delitos cuantitativamente distintos, sino cualitativamente diferentes. La distinción de carácter cuantitativo en razón de los distintos fines perseguidos (no de la intensidad de la violencia ejercida) fue puesta de relieve por el Tribunal Supremo en su Sentencia de 3 de julio de 1991 (Sandoval Coronado, 2018, p. 42, nota a pie núm. 20).

En la resolución acabada de referir, se caracterizaba a la rebelión como un comportamiento dirigido a atacar el normal desenvolvimiento de las funciones de legislar y gobernar, mientras que la sedición, afirmaba, tiende a atacar las secundarias de administrar y juzgar. Lo cierto es que si el comportamiento nuclear de ambos ilícitos es el mismo, pero tutelan bienes jurídicos diferentes y tienen fines distintos, obviamente, la conducta punible no es la misma.

$\mathrm{Si}$ atendemos a un análisis gramatical del término «alzamiento» parece que el Tribunal Supremo lo interpreta de forma similar. Así, en la ya tantas veces citada STS 10 de octubre de 1980, caracteriza al alzamiento como un «levantamiento, sublevación o insurrección...», particularidades que son absolutamente idénticas al alzamiento rebelde (Sandoval Coronado, 2013, p. 304). No obstante, el criterio adoptado por la mayoría de la doctrina para deslindar el alzamiento rebelde del sedicioso es el carácter que reviste, esto es, en la rebelión el alzamiento es violento y público, mientras que en la sedición el alzamiento es público y tumultuario. Nota común de ambas modalidades típicas es que el alzamiento es público, aunque en la sedición reviste también el carácter de tumultuario. A lo anterior cabe añadir que la conducta típica en el delito de sedición se caracteriza por tratar de impedir «por la fuerza o fuera de las vías legales...». Esto es de modo violento-«violencia, bien absoluta, bien compulsiva y tanto recayente sobre las personas como sobre las cosas» o "de modo ilícito, ilegítimo o ilegal y no a través de recursos o procedimientos de reclamación o de disconformidad que la Ley arbitre o prescriba». En palabras de la STS 10 de octubre de 1980, las particularidades que revisten el uso de la fuerza o el impedir "fuera de las vías legales» es la de impedir o dificultar la aplicación de las funciones de administrar y juzgar. En virtud de lo anterior, es inevitable concluir que, el legislador equipara el comportamiento violento con el que se lleva a cabo fuera de las vías legales, es decir, del tenor literal del precepto se desprende que el legislador atribuye el mismo desvalor a dos comportamiento que vienen presididos por formas distintas de llevar a cabo el comportamiento típico, esto es, una sedición pacífica (fuera de las vías legales) con una sedición violenta (por la fuerza) (Terradillos Basoco, 2002, p. 1146).

A este respecto, al margen de que el precepto diferencie entre el uso de la «fuerza» o "fuera de las vías legales» (Sánchez Tomás, 1999, p. 122), un sector de la doctrina considera que el alzamiento en la sedición es siempre violento (García Albero, 2008, pp. 1039-1040), por lo que carecería de relevancia penal la pacífica oposición colectiva a la ejecución de leyes o al ejercicio de las leyes, incluso cuando estuviera fuera del sistema legal de recursos o procedimientos de reclamación que la ley arbitre (Baucells Lladós, 2004, p. 2511). El elemento determinante de tal propuesta es la formulada en su día por Quintano Ripollés (1966, p. 556), para quien el adverbio tumultuariamente debía interpretarse en el sentido de «abierta hostilidad», de manera que solo resulte constitutivo del delito de sedición el alzamiento público llevado a cabo con violencia o, al menos, con intimidación, es decir con la amenaza de llevar a cabo actos de violencia. Por lo tanto, para la «abierta hostilidad» particularidad del levantamiento tumultuario, será irrelevante el 
carácter «gregario, amorfo, caótico, anárquico, inorgánico y desordenado o en tropel, aunque nada impediría, según opinión unánime, que de ser organizado y ordenado también se aplicará el precepto analizado» (STS 10 octubre 1980).

En suma, Quintano Ripollés considera que el adverbio «tumultuariamente» incluye tanto la violencia en sentido estricto como la intimidación; por ello, el alzamiento por la fuerza sería aquel en el que se emplea violencia física, mientras que el alzamiento fuera de las vías legales sería aquel que se realiza mediante intimidación, sin que ello signifique que el alzamiento sólo puede realizarse cuando esté desprovisto de un plan de ejecución (1966, p. 556). Es más, el alzamiento propio de la sedición no significa que este carezca de organización. Así, en la influyente Sentencia de 10 de octubre de 1980 la propia Sala considera que nada impediría «que de ser organizado y ordenado también se aplicara el precepto analizado». Criterio que mantiene igualmente en la Sentencia de 11 de marzo de 1994, donde manifiesta «si no existió entre los acusados una organización ni concierto previo relativo a las acciones a desarrollar en el Pleno Municipal...entonces los hechos juzgados no podrían entenderse como una sedición, que requiere una organización, planificación y designio de producir el alzamiento público contra la autoridad...». Una vez dicho lo anterior, creo que es oportuno puntualizar dos cuestiones, la primera de ellas es que la ausencia de «violencia» en la descripción típica del delito de sedición no significa que esta queda extramuros del ilícito sino todo lo contrario, ya que difícilmente pueden conseguirse los fines sediciosos sin recurrir a los medios violentos y, en segundo lugar, el hecho de que el carácter del alzamiento «tumultuario» solo se recoja en el comportamiento típico sedicioso, no puede interpretarse como que la sedición carezca de planificación o de organización (Sandoval Coronado, 2013, p. 306) ${ }^{9}$.

En definitiva, en los fines buscados, bien por los rebeldes bien por los sediciosos estaría la diferencia entre ambos alzamientos (Sandoval Coronado, 2018, p. 41).

\section{La maleabilidad del delito de sedición en el reciente tratamiento jurisprudencial}

Uno de los principios básicos del Derecho es que no se le puede obligar a decir lo que, en realidad, no dice ya que ello supondría, entre otras cosas, una vulneración del principio de legalidad. Sin embargo, a mi parecer, tanto el Juzgado Central de Instrucción núm. 3, como el Instructor del Tribunal Supremo en la Causa Especial núm. 20907/2017, en determinadas resoluciones judiciales relacionadas con lo que ha venido a denominarse el "procés», no han sido demasiado afortunados hasta el punto de atribuir a los delitos de rebelión y de sedición una «elasticidad» que contraviene cualquier lógica jurídica. En este sentido, no puede perderse de vista que cuando el Partido del actual Gobierno se encontraba en la oposición llegó a anunciar una proposición de ley para reformar el Código penal y con ello adecuar el delito de rebelión a lo que denominaba «el desafío independentista». La razón no es otra que la interpretación realizada por los Tribunales genera indiscutibles dudas acerca de su adecuación al principio de legalidad, todo ello al margen de la interpretación «macro extensiva» que le dispensan al concepto de violencia.

Atendiendo al objeto de estas páginas, no puedo realizar un análisis detallado de todas las resoluciones dictadas por la Audiencia Nacional en este

\footnotetext{
${ }^{9}$ Igualmente, López Garrido/ García Arán (1996, p. 202).
} 
asunto, sino que me detendré en algunas de las, a mi parecer, más significativas en relación con el delito de sedición.

4.1. El Auto del Juzgado Central de Instrucción núm. 3, de 27 de septiembre de 2017: las mixturas con el Código penal de 1973, la confusión con el delito de rebelión y la competencia de la Audiencia Nacional cuando el delito de sedición atente contra la forma de Gobierno

El Auto, en el que se acuerda incoar Diligencias Previas además de aceptar la competencia para el conocimiento de las actuaciones y la práctica de diligencias, se dicta como consecuencia de la denuncia que interpone el Ministerio Fiscal por la comisión de un pretendido delito de sedición como consecuencia de los hechos ocurridos en Barcelona los días 20 y 21 de septiembre de 2017 que, en síntesis, consistieron en que «una muchedumbre de personas se concentró ante los edificios registrados (Consejería de Economía, Consejería de Exteriores, Consejería de Gobernación, además de en la sede del PSC) con la finalidad de impedir por la fuerza a los agentes de la autoridad el legítimo ejercicio de sus funciones y el cumplimiento de las resoluciones judiciales...», además, continúa la resolución, de que se pincharon ruedas y se destrozaron diversos coches patrullas de la Guardia Civil y se impidió a los agentes y a los miembros de la comisión judicial abandonar los edificios tras los registros practicados. Hechos que en el Razonamiento Jurídico Segundo se valora que pudieran ser constitutivos de un delito de sedición, previsto y penado en el art. $544 \mathrm{CP}$.

Seguidamente, el Auto cita la imperecedera Sentencia del Tribunal Supremo de 10 de octubre de 1980 para concluir que el elemento subjetivo del delito de sedición "comprende la intención de conseguir uno de los fines ilícitos contemplados en el precepto, como es impedir la aplicación de las leyes o a cualquier autoridad, corporación o funcionario público, el legítimo ejercicio de sus funciones o el cumplimiento de sus acuerdos, o de las resoluciones administrativas o judiciales».

Consideraciones que, al margen de referir como precedente jurisprudencial una Sentencia donde la descripción típica y las finalidades del delito de sedición eran distintas al texto actualmente vigente, pueden suscribirse para el actual art. 544 $\mathrm{CP}$. Sin embargo, en el razonamiento siguiente afirma que el conocimiento del delito de sedición, cuando atenta contra la forma de Gobierno, es competencia de la Audiencia Nacional. Consideración que pretende sustentar con un malabarismo jurídico absolutamente insólito, como es el hecho de traer a colación el Título II del Libro II del CP de 1973: "Delitos contra el Jefe del Estado, su sucesor, altos Organismos de la nación y forma de Gobierno», para añadir que cabe entender que son delitos contra la forma de Gobierno los «actos encaminados o dirigidos a romper la organización territorial del Estado». Sin embargo, no es eso todo ya que concluye que «la descripción típica del delito de sedición en el Código penal vigente encajará en las conductas materiales descritas en el delito contra la forma de Gobierno si los actos se ejecutan con el propósito de cambiar ilegalmente la organización del Estado». Llegados a este punto, he de admitir mi perplejidad ya que la redacción actual del art. 544 nada refiere al «propósito de cambiar legalmente la organización del Estado» y, por lo tanto, a mi parecer, la imposibilidad material de calificar esos actos como un delito de sedición ya que este no contempla la hipótesis de declarar la independencia de una parte del territorio nacional.

Por otro lado, sobre la competencia de la Audiencia Nacional para conocer de estos delitos ya hemos referido que Dopico Gómez-Aller (2017), aborda con 
sólidos argumentos la discutible arrogación de competencias para la instrucción y enjuiciamiento de los mismos, por lo que no voy a abundar en ello. No obstante, una lectura detenida del Auto permite poner de manifiesto dos circunstancias que no pueden pasar desapercibidas. La primera de ellas se encuentra en el Razonamiento Jurídico Tercero, donde la Magistrada trae a colación el Auto dictado por el Pleno de la Sala de lo Penal de la Audiencia Nacional, de 2 de diciembre de 2008, quien consideró «que el conocimiento del delito de rebelión no era competencia de la Audiencia Nacional». Obsérvese como la Instructora se refiere al delito de rebelión no al delito de sedición, más allá de que pueda ser competente o no para conocer de ellos, a mi parecer evidencia su confusión en cuanto al comportamiento típico subsumible en ambos ilícitos y con ello calificar como sedición (no se olvide que la denuncia interpuesta por el Ministerio Fiscal se circunscribía al delito de sedición, no al delito de rebelión) hechos que no se compadecen con el tenor del precepto.

En segundo lugar, una muestra de la creatividad interpretativa del Auto es la siguiente afirmación: «Es claro que el legislador de 1985 quiso que el conocimiento de aquellos delitos que atentaren contra la forma de gobierno fuera competencia de la Audiencia Nacional, estableciendo con ello un marco competencial que no puede entenderse derogado por el hecho de haber sido modificada la nomenclatura contenida en el nuevo Código Penal». Otra cosa es, continúa, que el delito de sedición, actualmente ubicado entre los delitos contra el orden público, no tenga por objeto atentar contra la forma de Gobierno, o que se pretenda aplicar el art. 164 del derogado CP de 1973 o que, en fin, se interprete la voluntad del Legislador en el momento de aprobar la Ley Orgánica del Poder Judicial y se pretenda que los hechos objeto de las actuaciones son competencia de la Audiencia Nacional porque el art. 65 de la citada Ley Orgánica la contempla para enjuiciar los delitos contra la forma de Gobierno, a pesar de que, como se afirma en la resolución, la Ley se haya reformado hasta en ocho ocasiones y «ninguna de ellas ha modificado su contenido para hacerlo coincidir con la rúbrica de ningún título o capítulo de dicho texto legal».

Efectivamente, el Legislador no ha modificado en ese apartado el marco competencial de la Audiencia Nacional, pero de lo que no cabe ninguna duda es que esa deficiencia es reprochable en exclusiva a él mismo y que no es factible moldear su contenido para arrogarle una competencia a la Audiencia Nacional de la que carece; sin olvidar que el delito de sedición no tiene como objeto la alteración ilegal de la organización territorial del Estado ni declarar la independencia de una parte del territorio nacional.

4.2. El auto de la Sala de lo Penal de la Audiencia Nacional de 6 de noviembre de 2017: la corroboración del malabarismo jurídico y la confusión entre los delitos de rebelión, de sedición y la confirmación de la competencia de la Audiencia Nacional

El Auto de la Sala de lo Penal de la Audiencia Nacional de 6 de noviembre de 2017 resuelve el recurso de apelación formulado contra el de 27 de septiembre de 2017, confirmado en reforma por Auto de fecha 11 de octubre de 2017 donde, en resumida síntesis, se interesaba la inhibición del Juzgado Central de Instrucción núm. 3 y que este declinara su competencia a favor de los Juzgados de Instrucción de Barcelona.

Como se desprende de la rúbrica que encabeza el presente epígrafe, la Sala de lo Penal de la Audiencia Nacional confirma su competencia para instruir los hechos investigados, además de reafirmar la existencia de indicios de un delito de sedición. En efecto, la Sala afirma expresamente que comparte los «acertados razonamientos» de la Instructora, que justifican las competencias de la Audiencia 
Nacional, hechos que pudieran ser constitutivos de un delito de sedición «entendido como delito contra la forma de Gobierno»y, todo ello, me permito añadir, a pesar de que la citada rúbrica haya desaparecido del Código penal, que esos ilícitos abran los «Delitos contra el orden público» o que los derogados delitos contra la forma de Gobierno no compartan estructuralmente nada con la actual configuración típica del art. $544 \mathrm{CP}$.

En la misma línea de consideraciones, permítaseme insistir, el Tribunal se hace eco y asume como propia la ceremonia de confusión en la que incurre el Juzgado Central de Instrucción núm. 3. Así, vuelve a vincular a la sedición con sustituir al Gobierno de la Nación, con declarar la independencia y con despojar a la Corona de sus prerrogativas o facultades en Cataluña, enfatizando que ya no se trata únicamente de que los delitos de sedición sean competencia de la Audiencia Nacional (a pesar de que la Ley Orgánica 6/1985 del Poder Judicial no lo contempla), «sino porque el delito de sedición que en el caso concreto se trata de investigar puede atentar también contra la forma de Gobierno». Otra cosa es que la dicción literal de los arts. 544 y ss. CP vigente, ilícitos que se imputan a los investigados en esta causa, no prevean ni los comportamientos típicos que se les atribuyen, ni contemplen la finalidad que el Instructor y la Sala les arrogan.

No obstante, el Voto Particular a esa resolución formulado por el Magistrado De Prada Solaesa, es a mí parecer particularmente clarificador sobre las dos cuestiones polémicas que en ese momento procesal se dirimían: la competencia de la Audiencia Nacional y la calificación de los hechos como un delito de sedición. En primer lugar, aunque no nos detendremos en ello, cuestiona la competencia de la Audiencia Nacional ya que, afirma categóricamente, el sometimiento de la predeterminación de la competencia de los Tribunales al principio de legalidad estricta, admitiendo que, es cierto, existe un margen para la interpretación de la legalidad, "pero no para la sustitución de esta», y menos, como es el caso, estableciendo por vía jurisprudencial atribuciones competenciales que no existen para casos concretos y menos la creación de tribunales «ad hoc», concluyendo que no caben las interpretaciones extensivas de la competencia «por razones de oportunidad si no tienen suficiente amparo legal». Sin olvidar que el delito de sedición, cualquiera que fuera la intención última de los sujetos no ha sido competencia de la Audiencia Nacional, en ninguno de nuestros Códigos penales, ni ha sido considerado como un delito contra la forma de Gobierno. Entendiendo que el concepto de delitos contra la forma de Gobierno no puede «ser estirado a conveniencia» para encajar en ellos a cualquier delito contra la Constitución o «asimilados», sino únicamente a la forma en cómo la Constitución define el art. 1.3 la forma política de Estado, como «monarquía parlamentaria».

Por otro lado, por lo que respecta al delito de sedición y en la línea de lo aquí defendido, el Voto Particular afirma que el Instructor parece que esté creando una categoría jurídica inexistente ya que el delito de sedición, tal y como lo contempla el art. $544 \mathrm{CP}$, prevé en su descripción típica «únicamente» la finalidad de impedir la aplicación de la Leyes o el ejercicio de funciones a sujetos públicos, cumplimiento de acuerdos o resoluciones administrativas o judiciales, careciendo de ningún elemento teleológico ulterior como sí acontece con otras tipologías delictivas. Es verdad, continúa, que los sujetos activos de un delito de sedición tendrán una finalidad última para realizar los actos que llevan a cabo, pero esta será irrelevante para el Derecho penal a no ser que esa finalidad sea en sí misma delictiva, pero ya no será un delito de sedición sino otro distinto. Es más, puntualiza, si los tipos penales que pudiera tener en mente el Instructor son los delitos de rebelión, debería tener en cuenta las características y exigencias típicas de este delito y, con ello, una clara exigencia del elemento de violencia. 
4.3. El Auto del Juzgado Central de Instrucción núm. 3, de 19 de febrero de 2018 : más de lo mismo, la atribución al Comisario Jefe de la Policía Autonómica de un segundo delito de sedición y de un delito de organización criminal del art. 570 bis del Código penal

Mediante Auto de 19 de febrero de 2018 se atribuye al Comisario Jefe de la Policía Autonómica la condición de investigado por la comisión de un segundo delito de sedición como consecuencia de la celebración del referéndum del 1 de octubre y otro de un delito de organización criminal, con la particularidad de que le ya había sido atribuida esa misma condición por otro presunto delito de sedición en virtud de los hechos acaecidos los días 20 y 21 de septiembre de 2017.

En el Auto se afirma que se han recabado nuevos indicios que ponen de manifiesto «la existencia de una compleja y heterogénea organización unida por el propósito de lograr la secesión de la Comunidad Autónoma de Cataluña y su proclamación como República independiente alterando de esta forma la organización política del estado y con ello la forma de Gobierno, con clara contravención del orden constitucional y estatutario». En la resolución se describe la estrategia urdida por los distintos sujetos partícipes de un plan común para obtener la independencia y se le atribuye a la Policía Autonómica una actitud no sólo pasiva sino, se dice, que se mantuvo al margen de las actuaciones desarrolladas por la Guardia Civil, evitando intervenir incluso cuando alguno de sus miembros era agredido, además de obstaculizar la actuación de aquellas otras policías, llegando incluso a increpar y enfrentarse a alguno de los agentes de las Fuerzas y Cuerpos de Seguridad del Estado que en el ejercicio de sus funciones se encontraban en el lugar.

En todo caso, en lo que respecta a la finalidad del Comisario Jefe en los hechos se dice que era la de «facilitar la celebración del referéndum y con ello la proclamación de una república catalana, independiente de España, siendo consciente de que desarrollaba una actuación al margen de las vías legales, desatendiendo el mandato recibido desde el Tribunal Superior de Justicia de Cataluña y en contra de las decisiones adoptadas por el Tribunal Constitucional».

A mi juicio, está fuera de cualquier duda que la convocatoria y la celebración del referéndum del día 1 de octubre eran ilegales, que se desatendieron los mandatos del Tribunal Superior de Justicia ya que este ordenó a la Policía Autonómica que se impidiera el uso de locales o edificios públicos para la celebración del referéndum, que la actuación de la Policía Autonómica ese día fue de total inactividad, es indiscutible que se desatendieron las resoluciones del Tribunal Constitucional que, en suma, el proceder de la Policía Autonómica fue reprobable. Ahora bien, ¿constituye la actuación del Comisario Jefe un delito de sedición? Un delito de sedición que, entiendo, debería ser atribuido en comisión por omisión (nótese que la sedición es un delito de simple actividad mientras que los delitos en comisión por omisión son delitos de resultado), pero, al margen de la modalidad del comportamiento atribuible al Comisario Jefe, cabe preguntarse si concurren en ese caso los elementos típicos constitutivos del delito que se le arroga. Esto es, más allá de la desobediencia, creo que es sumamente controvertida la afirmación de que la finalidad del responsable operativo de la Policía Autonómica era la proclamación de la república catalana independiente de España, y que ello es constitutivo de un delito de sedición cuando ese propósito no se explicita en la descripción típica del delito del art. 544 CP. Sin embargo, más paradójico resulta 
que los hechos llevados a cabo con ese mismo propósito, por otros actores que se encuentran procesadas en la Causa Especial seguida en el Tribunal Supremo, se hayan instruido como un delito de rebelión.

A la vista de lo anterior, creo que no es difícil concluir que las resoluciones dictadas por la Instructora de la Audiencia Nacional suscitan algo más que dudas en relación a la concurrencia de los requisitos típicos de ese delito.

4.4. El corolario de lo anterior: el Auto de procesamiento del Juzgado Central de Instrucción núm. 3, de 4 de abril de 2018, y la imputación a los procesados, entre otros, de un delito de sedición.

En el referido Auto se acuerda el procesamiento del Comisario Jefe de la Policía Autonómica por dos delitos de sedición y uno de organización criminal, a otro de los investigados por un delito de sedición y a otros dos por un delito de sedición y uno de organización criminal. En el Antecedente de Hecho Cuarto se describe con detalle lo que se denomina la existencia de una compleja y heterogénea organización presidida por la finalidad de lograr la secesión de Cataluña del resto del Estado y su proclamación como República, la alteración de la organización política del Estado y de la forma de Gobierno, «con clara contravención del orden constitucional y estatutario».

Ahora bien, por lo que aquí interesa, es en el Razonamiento Jurídico Cuarto donde se califican los hechos atribuidos como un delito de sedición. En efecto, el inicio del Razonamiento se refiere a la ubicación sistemática del ilícito entre los delitos contra el orden público, reproduciendo literalmente el texto del art. $544 \mathrm{CP}$. Como no podía ser de otra manera se vuelve a citar la omnipresente Sentencia del Tribunal Supremo de 10 de octubre de 1980, se incide en que el alzamiento tumultuario característico de la sedición va dirigido a impedir, por la fuerza o fuera de las vías legales, la aplicación de las Leyes o cualquiera de las personas que en el mismo se relacionen el legítimo ejercicio de sus funciones o el cumplimiento de sus acuerdos, o de las resoluciones administrativas o judiciales. Concreta que el bien jurídico protegido es el orden público, entendido como «la paz y tranquilidad en las manifestaciones de la convivencia ciudadana». Igualmente se refiere al principio de autoridad como objeto de protección para acabar añadiendo que, en el supuesto de autos, «los delitos cometidos, además de atentar contra los bienes jurídicos que le son propios, suponen al mismo tiempo una ofensa contra la forma de gobierno».

A partir de aquí, la Instructora vuelve a abundar en la confusión entre los delitos de rebelión y sedición que ya había perfilado en resoluciones anteriores, como es el hecho de atribuir a los procesados unas finalidades que subsume en el delito de sedición que, en todo caso, no se enmarcan en la descripción típica del precepto. Aun así, constata la presencia de un dolo específico de los procesados de romper «la organización territorial del Estado», de modo que los actos realizados iban encaminados a violar la legalidad constitucional y a alterar la organización territorial del Estado, «por lo que en este caso deben ser también considerados como delitos contra la forma de Gobierno».

Hemos visto que la ubicación sistemática de los delitos de rebelión y sedición es distinta, que los objetos de protección de ambos ilícitos difieren o de que su comportamiento típico no es coincidente, lo cual no impide que vuelva a referirse a la sedición como «rebelión de segundo grado», descarta expresamente la presencia de la violencia en el comportamiento de los procesados, pero vuelve a abundar en la finalidad que, desde «la perspectiva de la antijuridicidad» resulta mucho más grave, «y en consecuencia un mayor desvalor del injusto, en cuanto la última finalidad de la 
misma, además de la propia de este tipo penal, es la prevista para los delitos de rebelión».

Llegados a este punto no puedo menos que volver a evidenciar un elemento que subyace en esta resolución que, asimismo, impregna las actuaciones desde el Auto de incoación de Diligencias Previas de 27 de septiembre de 2017, y es la confusión en la que incurre la Instructora al yuxtaponer los delitos de rebelión y sedición, ya que califica como sedición una modalidad del comportamiento típico que es exclusivamente propia del delito de rebelión, con la particularidad de que, más allá de que la denuncia de la Fiscalía General del Estado que da lugar a las actuaciones considere los hechos como sediciosos, la Instructora considera que en los hechos está ausente el elemento clave de la descripción típica del delito de rebelión, la violencia: «La concurrencia de esta doble finalidad, sin emplear violencia como sucede en el presente caso...».

Más adelante vuelve a referirse a la inagotable STS de 10 de octubre de 1980 donde, afirma, se relacionan los elementos que integran el delito de sedición, a pesar de que, como he insistido, en esa resolución se diriman unos hechos bajo la vigencia del preconstitucional CP de 1973, atribuyendo a la tan manida Sentencia unas afirmaciones que en ella no se recogen, como lo es: "Teniendo en cuenta que la soberanía nacional reside en el pueblo español, y en su representación en las Cortes españolas, no cabe mayor ataque al orden constitucional que pretender separar una parte del territorio nacional quebrantando de forma flagrante las normas constitucionales y sustrayendo al poder legislativo nacional su más genuina función».

Finalmente, no puedo concluir sin referir otra de las afirmaciones recogidas en el Auto de procesamiento que, a mi entender, ocasiona problemas de imputabilidad objetiva y subjetiva de hechos y situaciones a los sujetos procesados como es, refiriéndose a los hechos del 20 y 21 de septiembre: «se utilizó aquella masa de personas, aprovechando la innegable fuerza intimidatoria que produce la presencia física de un grupo compacto de multitud de personas dispuestas a oponer resistencia a los Agentes Policiales, incurriendo, en definitiva, en una conducta claramente subsumible en el delito de sedición previsto en el Código penal».

Lo dicho hasta ahora con el análisis sucinto de esas cuatro resoluciones dictadas por la Audiencia Nacional es evidenciar la confusión, cuando no superposición, entre los delitos de rebelión y sedición, flexibilizando los elementos típicos de éste último y atribuyéndole unas finalidades que no se encuentran previstas en el tipo.

\section{Bibliografía}

Álvarez García, F.J. (2014). La nueva reforma penal de 2013. Eunomía. Revista en Cultura de la Legalidad, 6, pp. 16-71.

Bages Santacana, J. (2018). El objeto de protección en el delito de rebelión del art. $472 \mathrm{Cp}$ desde la óptica del Modelo de Estado social y democrático de Derecho previsto constitucionalmente, en Estudios penales y criminológicos, núm. 38 , pp. 511-588.

Baucells Lladós, J. (2004). Sedición. En J. Córdoba Roda/ M. García Arán (Dir.) Comentarios al Código penal, T. II, (pp. 2509-ss.), Madrid-Barcelona, España: Marcial Pons. 
Carro Fernández-Valmayor, J.L. (1990). Sobre los conceptos de orden público, seguridad ciudadana y seguridad jurídica. Revista Vasca de Administración Pública, 27, pp. 9-26.

De Bartolomé Cenzano, J.C. (2002). El orden público como límite al ejercicio de los derechos y libertades, Madrid, España: Centro de Estudios Políticos y Constitucionales.

Dopico Gómez-Aller, J. (2017). ¿Es competente la Audiencia Nacional para conocer de los delitos de rebelión y de [algunos de] los delitos de sedición? Revista Electrónica de Ciencia Penal y Criminología, 19, pp. 1-21.

Fernández Rodera, F. (1996). Los delitos de rebelión y sedición. Diario la Ley, D128 , diario de 12 de abril.

Fernández Rodera, F. (2015). Sedición, en M. Gómez Tomillo/ A. M. Javato Martín (Dir.). Comentarios prácticos al Código penal, T. VI, pp. 403-ss. Pamplona, España: Thomson Reuters Aranzadi.

García Albero, R. (2008). Sedición, en G. Quintero Olivares (Dir.) Comentarios al Código Penal, T. III, 5a ed., pp. 1037-1041, Pamplona, España: Thomson Reuters Aranzadi.

García Rivas, N. (2007). Sedición, en A.I. Nieto Martín/ A. Pérez Cepeda (Coord.). Comentarios al Código penal, pp. 1059-1060, Madrid, España: lustel.

López Garrido, D., García Arán, M. (1996). El Código penal de 1995 y la voluntad del legislador, Madrid, España: Dykinson.

Manzanares Samaniego, J.L. (2017). El Código Penal en el proceso independentista de Cataluña. La Ley, núm. 9061, 16 de octubre.

Martín Retorillo, L. (1983). El orden público como límite al derecho de libertad religiosa, en M. Ramírez Jiménez (coord.). Bajo el signo de la Constitución, pp. 111-144, Madrid, España: Libros Pórtico.

Polaino Navarrete, M. (1996). Curso de Derecho penal español. Parte Especial, T. II, Madrid, España: Bosch.

Quintano Ripollés, A. (1966). Comentarios al Código penal, 2ª ed. Madrid, España: Editorial Revista de Derecho Privado.

Rebollo Vargas, R. (2018). Consideraciones y propuestas para el análisis del delito de rebelión $\mathrm{y}$, en particular, del delito de sedición: bien jurídico y algunos elementos del comportamiento típico. Revista de Derecho penal y Criminología, 19, pp. $139-177$.

Sánchez Tomas, J.M. (1999). La violencia en el Derecho penal, Barcelona, España: Bosch.

Sandoval Coronado, J.C. (2013). El delito de rebelión. Bien jurídico y conducta típica, Valencia, España: Tirant lo Blanch.

Sandoval Coronado, J.C. (2018). La política de orden público y el delito de sedición. El cronista del Estado Social y Democrático de Derecho, 75, pp. 38-43.

Terradillos Basoco, J. (2002). Voz "Sedición", en D. M. Luzón Peña (Dir.) Enciclopedia penal básica, Granada, España: Comares.

Viada y Vilaseca, S. (1926). Código penal reformado de 1870, T. III, $5^{a}$ ed., Madrid, España: Suárez. 